\title{
Declining Bargain Power: Streaming, Production, and Entertainment Labour
}

\author{
Shantharaju $S^{*}$
}

\begin{abstract}
The fluidity of time and space, diverse collection, and personalized recommendations of streaming (OTT players) would mean a lot to a viewer looking for instant entertainment. On the other hand, such transitions from traditional viewing platforms pose a diverse challenge to everyone involved in entertainment productions. The remote select button is replaced with a scrolling option, but the difference is in the platform's 'thinking' or analytical algorithm, which was not part of traditional TV or Cinema hall. This global shift might be beneficial to a few and yet, lowers the number of personnel involved in productions. This is a conceptual paper looking into the interaction between streaming and the entertainment industry labour.
\end{abstract}

Keywords: Streaming, Netflix, Entertainment, Labour, Challenges, Union.

\section{What Matters is On-Screen, not Off}

While arguing on the invisible labour in cinema, Michael Curtin and Kevin Sanson opine that "everything that matters happens on screen, not off... Those we hear least are the voices of labor" (Voices of Labor, 2017). Though it sounds gloomy, the reality is no different concerning any entertainment media. If this is the standard practice in cinema, even the producer is seldom identified on a small screen. The audience would have seen the name of the production house

* Department of Media Studies, CHRIST (Deemed to be University), Bangalore, India; shantharaju.s@christuniversity.in 
twice in a day. However, they would ignore such details except if the show or series is created by an individual with a reputation, who can effectively market the produced show, let alone any other individual involved in the production.

Each production involves hundreds of skilled, unskilled, creative individuals, ranging from a gaffer (light men) to a costume artist working for a specific piece. Over time, the industry has categorized itself into systematic departments like lighting, camera, direction, writing, execution, catering, travel, acting, artists, stunts, special effects, and many more depending on the size of production. The individuals doing work provide contributions that are greater than what they are paid for, with the aspiration of seeing their names in the credit rolls of the show. Yet a large section of entertainment labour remains anonymous. Being an anonymous contributor for an audience, there is a gradual shift in the fundamental roles that offer different avenues and closing certain others. Those who could upgrade skills, take up new roles like production managers, studio managers, or executive producers, thus moving up the industry ladder, resulting in a changing landscape of entertainment labour. This conceptual paper attempts to construct a discourse around such changing labour where the labour evolves through aggregation and shifting of productions of traditional media by OTT players. We cannot discuss the challenges of entertainment workers without changing platforms and switching content.

While writing about the shift in the entertainment industry, Lois Gray (2001) writes, "For entertainment workers, technology both creates and destroys jobs... There are not only winners for whom the number of jobs continues to grow but also losers - whole segments of the workforce being replaced." To a large extent, Gray's observations are nothing less than a reflection of the status quo of the current workforce involved in entertainment commerce. Gray's arguments were made almost two decades back when the cinema itself was in its nascent stages to adapt to digital creation from analogue-celluloid medium. 
Gray refers to how the musicians faded away with fewer recordings and videotapes and similarly once highly paid theatre projectionists disappeared with the appearance of autoplay technology. Now, in 2020, the impact on entertainment workers with OTT/streaming players and televised web platforms is far more complex than that of the aforementioned musicians or projectionists. We cannot summarize the change streaming platforms are making in a single statement as it is a mix of both constructive and destructive elements. If it is a boon for professional and amateur producers, many existing TV networks and operators have expressed their concerns over losing their revenues and work (Lobato \& Lotz, 2020). Incidentally, many Indian directors like Ram Gopal Varma, Anurag Kashyap, Farhan Akhtar are vigorously promoting their content on streaming platforms easing through the complete process of bringing the movie on a traditional producer-distributor-exhibitor's network and their lumbering share. In the Indian context, where the highest number of movies is made global, streaming involves more challenges than just bypassing theatrical release.

Out of three categories, Television, film, and Internet, the latter seems to have a hyper-stimuli characteristic (Roger Odin, 2012). Internet-based content platforms are potent enough to enrich content and divert the audience from the other two spaces, TV, and Cinema. The internet has enabled streaming platforms to offer 'snack culture,' which has been grabbed quickly and allows a viewer to become a 'reader,'; to consume content just like how someone reads a novel part by part in a convenient time (Odin, 2012). This change in viewing duration has affected the content of streaming (also the TV). According to an executive producercinematographer interviewed, today's web-series is shot more in Filmmaker Mahesh Bhatt's fashion. He always worked with multiple projects in the assembly line, controlled the shoots through phone calls, and got the shoot done by proxy (Shanti Kumar, 2019). The director is replaced by the production house in web-series, getting each episode done with multiple filmmakers. From the creator's point, it offers a communion production possibility. The labour force is hired from wherever it is convenient and controllable, moreover cheaper. 
Gray (2001) points out that the declining bargaining power of entertainment unions is because of media conglomeration and unions' fragmentation into many conflicting agendas. Gray also points out how technology has brought significant Telecommunication and Software companies to entertainment, which erases the production system followed hitherto. In the Indian context, one can see Reliance (Network 18, Jio TV), Viacom (Voot), Airtel (XStream), and Times group (MX player) as some examples of either extended streaming services of existing TV or a standalone streaming platform functioning for their sheer tech expertise. A streaming platform could offer beyond the movie/series experience with extras, spin-offs, off-camera videos, personal interviews and similar on-shoot rehearsal informal videos. (Roger Odin, 2012). The video's quality would be counted less, emphasizing on the audio part of it in small screens like mobile phones. OTT content could be of just one episode or a sequence, but it is a bowlful of varied versions. Such marketing efforts would still overlook the production process by minimizing the crew. In Odin's words, a tiny mobile viewing platform like a cell phone is helpful from the user's perspective. "The relationship between film and mobile phone works well in both directions" as a viewer breaks the space-time of movie experiences and moves towards the convenience similar to reading a book or a novel.

\section{Union's Passiveness}

Fundamentally, entertainment laborers could be considered creative (writers, musicians, dancers, and on-screen artists), technicians who represent highly skilled workforce and 'bluecollar' workers where rest would fall under (Gray, 2001). If the first two are paid through a contract and remunerated purely based on the calibre of the artist/technician-bargaining capacity of the producer, the latter has a minimal fixed daily wage like any unorganized sector's construction-contract jobs. There is a union for some set of workers like Television workers, stunt professionals, dancers, lighting men, food suppliers, scriptwriters. However, numerous 'service' workers are left out of such unions even though they provide creative labour like set design, patchworks, graphics, colouring, or if they are contract workers hired by huge studios for a project (Curtin and Sanson, 2017). 
It may provide a member of the labour union, the information on work demands and in parallel, mandate productions to hire workers through the association or the union. Sometimes, it is mandatory to hire workers through the association to apply for monetary subsidies like in the case of the State of Karnataka. The network of laborers, personal contacts, would grant an individual access to production. However, being a member of a union would not guarantee the workforce economic security except at the metalevel of organizational structure. At most, they get benefitted through insurance during accidents and seldom through governmental support like that with COVID19, where minimal support money is declared.

In most cases, such unions are a forum to solve the disputes between the individuals or, to an extent, protect investors' interest. Most organizations urge the members not to approach the media in case of a dispute (see the don'ts of CINTAA, Cine \& TV Artistes' Association). Many of the Hindi cinema labour organizations centred in Mumbai and other state-specific organizations are supposed to protect laborers' interest. However, these organizations provide the membership with an annual renewal fee and merely holding the membership might not provide certain days of guaranteed work like in Hollywood's unions.

The entire community of workers functions like an unorganized sector. An established producer owns a film unit or a production house which caters to television demands. He (as the cine investors are dominant men in India) provides work to a group of people working through the production agent/manager. Such managers take away their cut before paying the artists and other labours involved.

Bennington (2013) argues that "no actor is paid residuals in Bollywood due to lack of union presence," which he contrasts with Hollywood's binding with unions. "You always had to make sure you got paid on the last day of the shoot. Otherwise, one would never see the money" opines senior actor turned politician Anupam Kher, who has acted in around 400 films (as quoted by Mark Bennington, 2013). Except for the lead actors, no junior actor moves through a manager or paper in the Indian film industry. It is almost like prowling around the shooting spot daily, enquiring for that 
day's chances. If this is the level of disorganization in India's most prominent film industry, Mumbai, one can imagine the status of regional film industries.

While scrolling the cine worker's associations for Kannada cinema out of curiosity, it was found that 14 out of 19 organizations were registered from the same address in Bengaluru's Gandhinagar area where most of the Kannada producers have a functioning office. Having the same address for multiple organisations claimed to work for labourers proves an interest of one party or a group of people being dominant. On the other hand, not even a single association for anyone involved in the productions for streaming platforms is an even more shocking fact. The reason for this would be the traditional production houses shifting their work to OTT platforms, and other producers who are beginners in their trade, overlook the need for a union.

Two production executives were interviewed to confirm that the practice of monetary transactions are mostly through cash payments, and only higher amounts paid to actors and creative labourers like musicians happen through bank transactions. The labourers left with no other option but to obey unless they wanted to face an unpronounced ban from working in any unit (productions). Besides, sometimes associations demand cash payment over cheques issued by the producers, especially stunts and on-set workers. (Nitin Govil, 2013)

The regional television industry faces another threat of having a wolf in sheep's clothing. COVID19 halted the productions of both cinema and tele serials. The Indian television industry is diverse with more prominent regional languages than any other country in the world. To fill the daily slots, daily soaps were replaced with dubbed versions of other language soaps. Some of them were yesteryear's popular dramas, including Mahabharat, and Malgudi Days (these productions were initially produced in Hindi and dubbed versions aired in the first half of 2020). In Kannada channels alone (24 channels functioning in Kannada), 35 soaps never started the reproduction despite relaxing Covid19 restrictions for shoots by May 2020 (Ra. Nam, Chandrashekhar, and Rudresh Adarangi, Prajavani, 2020 July 30). If this is the dominant 
trend in television programming, it not only poses a cultural shift but replaces a considerable number of local employed labourers.

\section{The Good and Bad of Streaming Players}

Big budget productions can hire prominent stars as is the case with Bigg Boss reality shows or Hollywood directors like Martin Scorsese (Netflix). Those who lose out are small scale and mid-scale producers. The entertainment industry has created a secondary, tertiary employment network for full-time professionals; from the creative section to the technical team to amateurs who significantly contribute to the production numbers. For the producers of documentaries or indoor series, OTT works out to be a cheaper model as it allows for hyper-targeting a specific niche audience, which was never possible with the traditional model of productions. Documentaries were never mass marketed, but more are being produced today because they can hyper-target specific audiences, and some are even becoming hits (BCG, 2016).

Professional, amateur production houses are increasingly intent on producing content for OTT; one can check the production houses of MX Player's content. They may not be very fancy but offer erotica or thrillers to their craving audience. While speaking in a webinar, Kannada actor Samyukta Hornad, expressed "as an actress, I am happy that I get more screen space in web series than cinema. However, I am aware of thousands of junior artists, technical assistants who have nothing but returning to their natives" (July 10, 2020).

Interestingly, Microsoft, Sony, and Google's effort to stream gameplay creates another set of coding and designing jobs (Amor, 2019). The age of downloading seems to be out of fashion with better internet speeds and greater storage capacity in smartphones. Need to rip, download, and then wait to watch or play seems to be a tiring process when an instant viewing is possible with affordable pricing. If the gamification experiments of streaming experience are real, the near future creates opportunities for highly skilled gaming coders. Apart from this, Data analysts are the ones irreplaceable at the moment as every OTT platform needs them to hyper-target by 
understanding user psychology, creating a possible (appropriate) viewing profile for a user.

\section{The Disintegration of Production Mode}

OTT has introduced new types of content creators to the market. Traditional professionals who would have well-set production houses and produce content primarily for television consumption like Balaji or Excel, professional amateurs who work on a smaller budget and may not have access to big studios, and amateurs who are primarily YouTube content creators (Frank Arthofer, ÁkiHardarson, Martin Kon, Eric Lee, and John Rose, BCG, Sept 2016) have turned towards the OTT platform. Advertising based on-demand streaming (AoDS) like that of MX Player has opened up an opportunity for professional amateurs and amateurs to try their luck by producing mini-series, typically between 10-20 minutes.

Mostly, these professional amateurs are a small group of individuals with similar interests rarely working with unknown people. There is a steep increase in amateurs turning into professional amateurs since the phrase 'cinema grammar' is obsolete now, especially as we are born into the language of cinema itself (Roger Odin, 2012). Anyone who has used a smartphone is aware of what a visual sequence is. The metaphor of 'camera-pen' is a reality and not an overtly expensive affair to make a film (Odin 2012 quoting 1949's Astruc's assertions on the invention of $16 \mathrm{~mm}$ cameras).

The length of the web-series would give a sense that the targeted consumers are mobile, and would watch such media while in transit, outside the home or on their cell phones. When everything converges on a mobile screen, it is essential to create suitable content for the viewing space. Here, someone who could produce content irrespective of being a professional or amateur, would make a profit. Vox videos, travelogues like that of Hopping Bug, are a classic example of using public forums like YouTube to push content.

Web series like Naked, Mastram, FBuddies, GandiiBaat are produced to offer instantaneous entertainment, with storylines that 
surround age-old sexual desires, and ever exploitative sleazy content. The popular argument of advertising producers, 'sex sells' is true to web-series. With content creation, such content created by smaller studios, film enthusiasts, amateur filmmakers with or without a prior grounding in the film industry, if it is a hit, such teams will turn into professional studios, again away from the film industry circle's typical functioning. From scriptwriting to editing, most of the work would be carried out by such pro-ams, leaving out the opportunity to turn them into big productions employing many people.

On the other hand, many television networks are attempting to step into digital space to cater to the changed platform's appeal. Television channels launching OTT service is mostly an extension of the traditional TV program pattern. This aggression of launching streaming makes sure their audience is still hooked despite the changed viewing space.

\section{Transforming TV content, resized workforce and minimal web series}

Streaming options do not alone offer the consumer an unfamiliar experience. It has altered the role of content creators and shifted the traditional modes of production, affecting every individual involved in the entertainment industry. In a country like India, where entertainment is the largest employer bypassing railways (Piyush Roy, 2019), the impact of streaming players cannot be concluded as positive or negative on the labour force. It has to address both sides. Despite few new releases, the pandemic (between April-May 2020) has pushed both streaming and TV to their all-time high viewing, $65-70 \%$, and $20 \%$, respectively (The Verge, 2020, The Economic Times, 2020). Though both have acquired audiences, the streaming players have gathered more. However, there was no job for those dependent on production departments from set work to travel service since there were no productions.

OTT's viewing pattern puts pressure on TV and cinema in two ways; either the traditional TV content should be as alluring as a series like the Game of Thrones with high-quality productions, or it 
should cut down the production cost, but create an ever-increasing number of productions to include the diverse audience. CNN Business reports (May 20, 2019) 44.2 million viewers per episode for the last season of Game of Thrones, increasing with delayed viewing over $\mathrm{HBO}$ Go and $\mathrm{HBO}$ Now. In contrast, what competes with such euphoria is sports. If it is soccer for European countries like Italy and France, it is cricket to India. Sports, cinema, and televised dramas were the bread and butter of the television industry. These contents have been moving away from the television screen to streaming platforms. Hotstar would have been aware of this trend and thus pushed sports towards prematurely streaming convergence and capitalized successfully in the sports section. Parallel to it, Netflix and Amazon Prime moved towards acquiring the distribution rights of Indian series (predominantly Hindi). If this is the global players' domestic interaction, the question of what will happen with the local cinema, inland entertainment consumption, and state-specific traditional television content is a concern of the hour.

One can notice traditional television channels increasingly taken over by bigger networks, and programming is moving towards reality shows and game shows. These networks could afford regionally famous stars like Kamal Hassan (Tamil), Mohanlal (Malayalam), Salman Khan (Hindi) Mithun Chakraborty (Bengali) Nagarjuna (Telugu) and Sudeep (Kannada), Mahesh Manjrekar (Marathi). Such reality shows are produced for both Television and the network's online platforms like Voot, (Viacom group) and Hotstar (Star). The Zee group, which runs the OZEE OTT platform, invested in contest-based shows like Sa Re Ga Ma Pa, Dance Indian Dance, and soaps. On the other end of the list, prominent television networks like Sun Network and Star group had a profusion of reality shows and televised dramas.

The content is moving towards two extreme ends. Reality shows are not creating any alternative employment. Instead, they restrict the number of people in the production as it is confined to in-house drama and partially pushed by the person hosting it, who is a wellknown actor within the state. With soaps, the budget seems to be confined and pressurized to work within the tight budget, the creators now rely on scenes of conversation. Apart from television 
networks, traditional networks like Balaji productions started their digital platform, ALTBalaji, to keep pace with the digital migration.

Interestingly, erotic content like that of Gandi Baath (ALTBalaji) and Mastram (MXPlayer) was highly viewed, with both platforms registering a significant spike in their viewership during current Pandemic (Lata Jha, July 2020, Livemint). They produced both the aforementioned web series on a low budget and gained a considerable share of their viewership from small towns which rarely had access to such content. These newer Indian OTT entrants cleverly exploit the demand. In the entire process, those who were technically skilled were in demand, leaving behind those of the semi-skilled and unskilled labour forces employed by large productions.

\section{The gain games}

The increased content (rather could be termed as converging contents on a single platform) might adversely affect the number of jobs. A classic report as early as 2016 on North American telecommunications by Frank Arthofer, Martin Kon, Eric Lee, John Rose, and ÁkiHardarson, (BCG, 2016) indicate the same. The concerns expressed in the western context are valid to the Indian entertainment industry. However, the challenge for the streaming players is the multicultural productions rooted in television programming and the eventual step out into digital platforms. The television industry survived through the subscription and advertising support model. Decreased sponsorship is pushing programmers to increase the focus towards subscription models of DTH or TV apps. Sun NXT, a streaming platform of south India's biggest television network, struggling to cope with the digital challenge despite having a prominent regional market share. If such traditional players don't bailout, the impact will be on the unseen community of professionals; many content creators solely dependent on production houses' remuneration would be thrown out of the industry. What happened to the music industry (from cassette to CDs to streaming) could be a reference point to understand the consumption and production pattern of television content currently (Farid Ben Amor, 2019). 
With greater content, Indian productions could not reach the quality and breadth of western productions like that of Stranger Things, Narcos series of Netflix or Masters and Sex of Prime, Game of Thrones on $\mathrm{HBO} \mathrm{Go}$, or it is re-run on Hotstar. According to BCG's 2016 report, the OTT players are pushing the traditional players to produce high-quality content. Fantasy dramas and teenbased programming which are binge-watch worthy are the content receiving diverse investment at present. Such programming is way far from an Indian perspective. BCG report points out the similar experience of Britain. What OTT had left out was the Indian melodrama content, which has been picked up by the television channels.

The top 30 companies that did well even during the pandemic comprise Amazon Prime and Netflix, which contrasts with the declined functioning of the television industry (Steven Zeitchik, July 2020, TWP). If Television had to re-telecast their older episodes during the Pandemic restrictions, the streaming platforms had something to offer for every audience, including new releases snatched from touring schedules. However, the contents of these giant OTT players are aimed at a national level, if not a global scale, and appeals to every user. Hence the content acquired or produced across the countries and language, be it Korean or Spanish, are watched by anyone who could read English subtitles. Korean dramas, narratives of Mexican-Columbian drug cartels, and Spanish crime thrillers have a large audience on Netflix and would remain the top trending show for a very long time, recommending them to subscribers on the initial page. These streaming originals might create jobs, but the other distributed content (any content other than streaming's originals) is fundamentally outsourced and does not benefit the local workforce. A Spanish erotic crime drama, or a Columbian Narco series doesn't add to the local workforce. Instead, they perpetuate existing streaming libraries by monopolizing their audience base among native language speakers and cultivate cult viewing habits in other countries. 


\section{Conclusion}

In July 2020 alone, at least ten movies were released including some from reputed productions like Anurag Kashyap's Choked, Vidya Balan's Shakuntala Devi, Amitabh Bachchan's Gulabo Sitabo, Raat Akeli Hai, Gunjan Saxena, Sufiyum Sujathayum, PRK production's Law, French Biryani which need not go through the distributorexhibitor maize, decreasing the number of jobs necessary in theatres. If an average theatre employed ten people to run the show, the pandemic has affected at least 1,30,000 screen dependent employers.

Labour laws in India have been highly fluid in the recent past with many amendments. The industry seems to have the upper hand over the workers. However, in the entertainment industry, labour laws are always fluid and their application to Stuntmen, artists, Lightman, driver's association, security, insurance are rare. Moreover, the film industry has always been a very closely connected industry and has remained a non-reachable entity when approached to ensure the holistic security of a worker. In such situations, streaming platforms are without a doubt beneficial to small and medium scale filmmakers.

These platforms act as another avenue of distribution but may not contribute to the creation of more production houses and more employment. Web series could increase the moderate number of jobs, but the entertainment industry has always been an unorganized sector and would function as unorganized with more diverse content catering to diverse cravings. The space existed for collective bargaining for better payroll has decreased or disintegrated with the introduction of streaming platforms.

\section{References}

Arora, S. (2020, July 5). Insanely Expensive Indian Web-Series Produced by OTT Giants That Gave Movies A Run for Their Money, MENSXP.

Bennington, M. (2013). Inside Bollywood: With more than a billion fans, the Hindi film industry is built on family ties and handshake agreements. The Virginia Quarterly Review, 89(1), 28-45. Retrieved August 2, 2020, from www.jstor.org/stable/26446641 
Curtin, M., \&Sanson, K. (Eds.). (2017). Voices of Labor: Creativity, Craft, and Conflict in Global Hollywood. Oakland, California: University of California Press. Retrieved July 29, 2020, from www. jstor.org/stable/10.1525/j.ctt1pq347f

Frank Pallotta, C. (2020). 'Game of Thrones' finale sets new viewership record. Retrieved July 28, 2020, from https://edition.cnn.com/

Amor Ben, F. (2019, July 24). After music and TV, what is the future of streaming? World Economic Forum. Retrieved July 28, 2020, from https://www.weforum.org/

Arthofer, F, Kon, M, Lee, E, Rose, J, and Hardarson, A. The Future of Television: The Impact of OTT on Video Production Around the World. (Report 2016). BCG. Retrieved July 28, 2020, from https://www.bcg.com/

Edwards, C. (2015). Lighting levels for isolated intersections: Leading to safety improvements (Report No. MnDOT 2015-05). Center for Transportation Studies. Retrieved from http://www.cts.umn.edu/

Govil, N. (2013). Recognizing "Industry". Cinema Journal, 52(3), 172-176. Retrieved August 1, 2020, from www.jstor.org/stable/43653119

Gray, L. (2001). Entertainment Unions Tune-up for Turbulent Times. New Labor Forum, (9), 122-131. Retrieved July 30, 2020, from www.jstor.org/stable/40342322

Jha, L. (2020). Streaming sites gain from adult content during COVID. Retrieved August 14, 2020, from https://www.livemint.com/

Julia Alexander, J.(2020, July 16). The Verge. Netflix adds another whopping 10 million subscribers but warns growth may slow. (2020). Retrieved July 28, 2020, from https:/ /www.theverge.com/

Kumar, Shanti. (2019). 4. Film/City: Cinema, Affect, and Immaterial Labor in Urban India. 10.1525/9780520964808-006.

Lobato, R., \& Lotz, A.D. (2020). Imagining Global Video: The Challenge of Netflix. JCMS: Journal of Cinema and Media Studies 59(3), 132-136. doi:10.1353/cj.2020.0034.

Morgan, B. (2020). What Is The Future Of Television? Forbes. Retrieved July 28, 2020, from https:// www.forbes.com/

Nam, Ra. Chandrashekhar and Adarangi, R. Prajavani, (2020 July 30). Retrieved from http://epaper.prajavani.net/

Odin, R. (2012). Spectator, Film, and Mobile Phone. In Christie I. (Ed.), Audiences (pp. 155-169). Amsterdam: Amsterdam University Press. DOI:10.2307/j.ctt46mww7.15

Singh, D. (2020). How is coronavirus impacting the streaming platforms with an increasing appetite? Financial Express. Retrieved July 28, 2020, from https://www.financialexpress.com/ 
Vincendeau, G. (2000). Max Linder: The world's first film star. In Stars and Stardom in French Cinema (pp. 42-58). London: Bloomsbury Academic. Retrieved July 28, 2020, from http://dx.doi.org/ 10.5040/ 97814725 97724.ch-002

Zeitchik, S. (2020 July 17, 2020). Netflix added 10.1 million subscribers this spring as people around the world stay. Washington Post. Retrieved from https:/ / www.washingtonpost.com/ 